\title{
Editorial: Would you like to be cited more? Write about social networking sites
}

\author{
David Smahel ${ }^{1}$, Kristian Daneback ${ }^{2}$ \\ ${ }^{1}$ Faculty of Social Studies, Masaryk University, Brno, Czech Republic \\ ${ }^{2}$ Department of Social Work, University of Gothenburg, Gothenburg, Sweden
}

Dear researchers, colleagues, and readers interested in research on cyberspace,

We are honored to present the July issue (2-2015) of Cyberpsychology: Journal of Psychosocial Research on Cyberspace. In this issue, we present five articles which are methodologically diverse - the authors used surveys, experimental design, and one article is a theoretical overview of empirical evidence. Articles were also written by authors from three different continents: Europe, North America, and Asia. We note that we would also be happy to publish articles from other continents, i.e. South America or Africa, to increase territorial diversity. In this editorial, first we will introduce the five articles and next, we will show the analyses of article citations from our journal, based on Google Scholar. Last, but not least, we will inform about the increases of indicator which we got from the Scopus database (operated by Elsevier).

The first article, "Beauty in the eye of the beholder? Attractiveness in a virtual world" (Guan, Subrahmanyam, Linares, Cheng), examines whether traditional offline gender biases regarding physical attractiveness and status transfer to Second Life. The authors conclude that, in line with offline norms, female avatars high in physical attractiveness are rated as more attractive, regardless of status. But for male avatars, participants rate higher attractiveness if avatars have higher status!

The second article, "The benign online disinhibition effect: Could situational factors induce self-disclosure and prosocial behaviors?" (Lapidot-Lefler, Barak), focuses on the benign effects of disinhibition and examines the effects of anonymity, invisibility, and the lack of eye contact on inducing self-disclosure and prosocial behaviors. The authors, for example, reveal that interaction between anonymity and invisibility has a significant effect on the revealing of emotions and that the interaction between anonymity, invisibility, and the lack of eye contact has significant effects on the total self-disclosure score.

In the third article, "Religiosity, sexual myths, sex taboos, and pornography use: A cross-national comparison of Polish and German university students" (Martyniuk, Dekker, Sehner, Richter-Appelt, Briken), the authors compare the pornography use of students in two culturally different European countries, and investigate associations with religiosity, sexual myths, and sex taboos. The authors conclude that associations between pornography use and religiosity is ambiguous. For example, attending church is negatively associated with age at first contact and pornography use. But the intrinsic religiosity is correlated with a lower frequency of pornography use for females and with a higher frequency for males.

The fourth article, "Coping through blogging: A review of studies on the potential benefits of weblogs for stress reduction" (Petko, Schmitz, Totter, Hermann, Guttormsen), brings an overview of the empirical evidence for the potential effects of reflective weblog writing for coping with stress. The authors analyzed 17 relevant studies and reveal that the public nature of weblogs opens up a variety of possibilities for both problem-focused and emotion-focused coping, most importantly through social support. The authors also note that it remains unclear if and how the benefits of self-initiated blogging can be transferred to more formal settings. 
The fifth article, "The relationship between Facebook attachment and obsessive-compulsive disorder severity" (Lee, Park, Tam), explores how Social Networking Sites use may be associated with obsessivecompulsive disorder (OCD), with the inclusion of obsessive-compulsive beliefs as a mediator. The authors conclude that Facebook use contributes to OCD severity through obsessive-compulsive beliefs as the mediator. The study also extends the finding that Facebook use may resemble a form of obsessivecompulsive behavior, mediated by obsessive beliefs. The authors suggest that their findings may indicate that the notion of Facebook addiction is obsolete.

We believe you will find all five published articles to be interesting contributions to the current scholarship! Next we will introduce you to our analyses of citations.

We were curious which articles have been cited most in our journal history and, because only Google Scholar has indexed all of the articles from the journal since its establishment in 2007, we decided to run the analyses in this search engine. If you are interested, you can see the details of our search query here.

It is also necessary to note that the overall number of citations depends on the year of publication; therefore, older publications logically have an advantage. But if we divide the number of citations by the number of years from publication of the article, the results were not significantly different.

The most cited article, "User descriptions and interpretations of self-presentation through Facebook profile images" written by Michele M. Strano in 2008, got so far 151 citations. The second-most cited article, "Constructing the self through the photo selection-visual impression management on social networking websites" written by Andra Siibak in 2009, got 111 citations. The third-most cited article, "The privacy paradox on social network sites revisited: The role of individual characteristics and group norms" written by Sonja Utz and Nicole Krämer, got 93 citations.

Concerning the themes of the articles, five of the six most cited articles are about Social Networking Sites (SNS). It seems that writing about social networking increases the probability that the document will be cited. Also, the following themes and key words are very successful with respect to citations: selfpresentation, construction of virtual self, self-disclosure, privacy, and cyberbullying issues. But it is clear that also quality of the article matters! Plus, the popularity of themes is changing and such citation indexes have a high delay in the indication of popularity. So, who knows which themes will be most cited in the next five years?

Interestingly, we also looked at the number of visitors of first three most cited articles in the web-system which is hosting the journal and the article by Michele Strano got 90,365 visitors, the article of Andra Siibak 76,580 visitors, and the article of Sonja Utz and Nicole Krämer 60,547 visitors. These are really high numbers!

But there is also another piece of good news concerning our journal: there has been an increase to the $\mathrm{SJR}$ indicator, which is assigned from the Scopus database, and there has also been an increase to the indicator "Cites per document in last two years". You can look at the complex information about Cyberpsychology at the Scopus web pages here.

Concerning the SJR indicator, we are 118th from 216 journals in the category "Psychology (miscellaneous)". That means that we are currently in the third quarter of journals, and we are improving quickly and on the edge of moving into the second quarter. Interestingly, the indicator "Cites per document in last 2 years" (which is computed using the same formula as the journal impact factor from Thomson Reuters) is currently 0.938 for our journal. This is a very nice number for a journal which has been included in Scopus for only three years. That means that our articles have a solid numbers of citations!

But, because our lives are not only virtual, we will also be happy to meet you personally at the 13th Conference on "Cyberspace" in Brno on November 27-28 (see http://cyberspace.muni.cz). We will be happy to discuss your possible manuscripts, but also the various aspects of the research on cyberspace!

All the best,

David Smahel, editor

Kristian Daneback, associate editor 


\section{Issue Content}

Article 1:

Editorial: Would you like to be cited more? Write about social networking sites!

David Smahel and Kristian Daneback

doi: $10.5817 /$ CP2015-2-1

Article 2:

Beauty in the eye of the beholder? Attractiveness in a virtual world

Shu-Sha Angie Guan, Kaveri Subrahmanyam, Kevin Linares, and Roy Cheng

doi: $10.5817 /$ CP2015-2-2

Article 3:

The benign online disinhibition effect: Could situational factors induce self-disclosure and prosocial behaviors?

Noam Lapidot-Lefler and Azy Barak

doi: $10.5817 /$ CP2015-2-3

Article 4:

Religiosity, sexual myths, sex taboos, and pornography use: A cross-national comparison of Polish and German university students

Urszula Martyniuk, Arne Dekker, Susanne Sehner, Hertha Richter-Appelt, and Peer Briken

doi: $10.5817 / C P 2015-2-4$

Article 5:

Coping through blogging: A review of studies on the potential benefits of weblogs for stress reduction

Dominik Petko, Nives Egger, Felix Michael Schmitz, Alexandra Totter, Thomas Hermann, and Sissel

Guttormsen

doi: $10.5817 / C P 2015-2-5$

Article 6:

The relationship between Facebook attachment and obsessive-compulsive disorder severity Soon-Li Lee, Miriam Sang-Ah Park, and Cai-Lian Tam

doi: $10.5817 /$ CP2015-2-6

\section{About Journal}

The 'Cyberpsychology: Journal of Psychosocial Research on Cyberspace' is a web-based, peer-reviewed scholarly journal. The first peer-reviewed issue was published in September 2007. The journal is focused on social science research about cyberspace. It brings psychosocial reflections of the impact of the Internet on people and society. The journal is interdisciplinary, publishing works written by scholars of psychology, media studies, communication science, sociology, political science, nursing, ICT security, organizational psychology and also other disciplines with relevance to psychosocial aspects of cyberspace. The journal accepts original research articles, as well as theoretical studies and research meta-analyses. Proposals for special issues are also welcomed.

The journal is indexed with SCOPUS, ERIH PLUS, EBSCO Academic Search Complete, the Directory of Open Access Journals and the Czech Database of Scientific Journals.

The articles in Cyberpsychology: Journal of Psychosocial Research on Cyberspace are open access articles licensed under the terms of the Creative Commons Attribution Non-Commercial License which permits unrestricted, non-commercial use, distribution and reproduction in any medium, provided the work is properly cited.

\section{Editor}

Prof. David Smahel, M.Sc. et Ph.D., Faculty of Social Studies, Masaryk University, Czech Republic

E-mail: smahel(at)fss.muni.cz 


\section{Associate Editor}

Prof. Kristian Daneback, Ph.D., University of Gothenburg, Sweden

E-mail: kristian.daneback(at)socwork.gu.se

\section{Editor Assistant}

Lenka Dedkova, M.A., Faculty of Social Studies, Masaryk University, Czech Republic

E-mail: Idedkova(at)fss.muni.cz

\section{Editorial Board:}

Prof. Kaveri Subrahmanyam, Ph.D., California State University, Los Angeles, USA

Prof. Herbert Hrachovec, Ph.D., University of Vienna, Austria

Prof. Dr. Micheline Frenette, Universite de Montreal, Canada

Prof. Alexander E. Voiskounsky, Ph.D., Lomonosov Moscow State University, Russia

Prof. Michael W. Ross, Ph.D., DrMedSc, MPH, MPHEd, University of Texas, Houston, USA

Prof. Petr Macek, CSc., Masaryk University, Czech Republic

Prof. Olle Findahl, World Internet Institute, Sweden

Prof. Jochen Peter, Ph.D., University of Amsterdam, Netherlands

Prof. Veronika Kalmus, Ph.D., University of Tartu, Estonia

Prof. Joshua Fogel, Ph.D., Brooklyn College of the City University of New York, USA

Prof. Gustavo S. Mesch, Ph.D., University of Haifa, Israel

Michelle Wright, Ph.D., Masaryk University, Czech Republic

Václav Štětka, Ph.D., Charles University, Czech Republic

Andra Siibak, Ph.D., University of Tartu, Estonia

Adjunct Prof. Birgit U. Stetina, Ph.D., University of Vienna, Austria

Lukas Blinka, Ph.D., Masaryk University, Czech Republic

\section{Advisory Board:}

Prof. Bente Traen, Ph.D., University of Oslo, Norway

Prof. Charles Ess, Ph.D., University of Oslo, Norway

Prof. Dr. Ilse Kryspin-Exner, University of Vienna, Austria

Prof. PhDr. Jan Jirák, Ph.D., Charles University, Czech Republic

Prof. Vasja Vehovar, Ph.D., University of Ljubljana, Slovenia

Prof. Larry D. Rosen, Ph.D., California State University, USA

Prof. Patricia M. Greenfield, Ph.D., University of California, USA

Prof. Peter K Smith, University of London, England

Prof. Nicola Döring, IImenau University of Technology, Germany

Prof. Kimberly Young, Ph.D., St. Bonaventure University, USA

Prof. Jos de Haan, Ph.D., Erasmus University, Netherlands

Prof. Zbyněk Vybíral, Ph.D, Masaryk University, Czech Republic

Prof. Monica Whitty, Ph.D., University of Leicester, UK

Prof. Alistair Duff, Ph.D., Edinburgh Napier University, Scotland

Assoc. Prof. Alfred Choi, Ph.D., Nanyang Technological University, Singapore

Prof. Thurasamy Ramayah, Universiti Sains Malaysia, Malaysia

Assoc. Prof. Neil Coulson, Ph.D., The University of Nottingham, UK

Assoc. Prof. Kenneth C. C. Yang, Ph.D., University of Texas at El Paso, USA

Assoc. Prof. Sun Sun Lim, Ph.D., National University of Singapore, Singapore

Prof. Sameer Hinduja, Ph.D., Florida Atlantic University, USA

Assoc. Prof. Jana Horáková, Ph.D., Masaryk University, Czech Republic

Assoc. Prof. Radim Polčák, Ph.D., Masaryk University, Czech Republic

Assoc. Prof. Pille Pruulmann-Vengerfeldt, Ph.D., University of Tartu, Estonia

Assist. Prof. Alexander Schouten, Ph.D., Tilburg University, Netherlands

Assist. Prof. Ewa S. Callahan, Ph.D., Quinnipiac University, USA

Assist. Prof. Regina van den Eijnden, Ph.D., Utrecht University, Netherlands

PhDr. Ing. Petr Soukup, Charles University, Czech Republic

Janis Wolak, Ph.D., University of New Hampshire, USA

Francesca Romana Seganti, Ph.D., Sapienza University of Rome, Italy

Jeff Gavin, Ph.D., University of Bath, UK

Hana Macháčková, Ph.D., Masaryk University, Czech Republic 
Michael Fenichel, Ph.D., New York, USA

Leslie Haddon, Ph.D., London School of Economics, UK

Monica Barbovschi, Ph.D., Masaryk University, Czech Republic

Jan Širǔček, Ph.D., Masaryk University, Czech Republic

\section{Publisher}

Masaryk University, Faculty of Social Studies

Jostova 10, 60200 Brno

Czech Republic

\section{Publication Schedule}

Four issues per year: two regular issues (in July and December) plus two special issues (between regular issues)

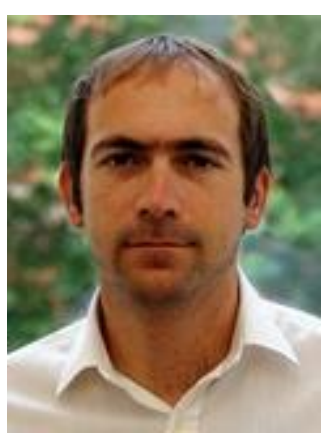

David Smahel, Ph.D. is the Professor at the Institute of Children, Youth and Family Research, Masaryk University, the Czech Republic. He directs the workgroup "Cyberpsychology" (http://www.cyberpsychology.eu/team) which researches socialpsychological implications of the internet and technology. Current research focuses on adolescents' and adults' internet use, the online risks of children and adolescents, the construction of online identities and virtual relationships, and online addictive behavior. He is editor of Cyberpsychology: Journal of Psychosocial Research on Cyberspace and has co-authored book Digital Youth: The Role of Media in Development (Springer, 2011). Smahel also published in several international journals such as Developmental Psychology, Cyberpsychology \& Behavior, Zeitschrift für Psychologie, European Journal of Developmental Psychology and others. He is also author of several book chapters, such as in Encyclopedia of Cyber Behavior, Encyclopedia of Adolescence, Internet Addiction: A Handbook and Guide to Evaluation and Treatment, Gesundheit und Neue Medien etc.

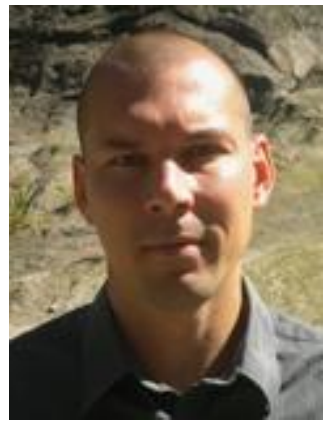

Kristian Daneback, Ph.D. is the Professor of Social Work at the University of Gothenburg, Sweden and in the Faculty of Social Studies at Masaryk University in Brno, Czech Republic. His main field of research is sexuality and in particular internet sexuality, but he is also interested in other internet related phenomena such as parenthood and the internet, cyberbullying, and how the internet can be used to collect qualitative and quantitative data. Daneback has published his research in several well known international journals such as Archives of Sexual Behavior, Cyberpsychology, Behavior, \& Social Networking, Journal of Sexual and Relationship Therapy, Journal of Bisexuality, and Sexual Addiction \& Compulsivity. In addition, he is a reviewer for journals such as Journal of Sex Research, Journal of Computer Mediated Communication, Pediatrics, Sex Roles, and Sexual Reproduction \& Health Care. Currently he serves as the Associated Editor of Cyberpsychology: Journal of Psychosocial Research on Cyberspace and is a Board Member of the Open Journal of Communication and ISRN Family Medicine. Daneback is also a member of the International Academy of Sex Research and the Association of Internet Researchers. 